\title{
PENGARUH DEBT RATIO, DIVIDEN PAY OUT RATIO, RETURN ON \\ EQUITY, PERUMBUHAN LABA, UKURAN KORPORASI, DAN \\ PERPUTARAN KAS OPERASI TERHADAP PER \\ (Studi Di Korporasi Sektor Manufaktur yang Listing di Bursa Efek
}

Indonesia Jangka Waktu 2009 - 2012)

\author{
Herlambang \\ Fakultas Ekonomi, Universitas Pamulang \\ herlambanghery@yahoo.com
}

\begin{abstract}
The mean of this research is examine influence debt ratio, dividend payout ratio variable, return on equity variable, earnings growth, size, and operating cash flow on price earning ratio $(P E R)$ in finance and manufacturing companies in Indonesia Stock Exchange in the period of year 2009 to 2012. The population in this study is the company in the sector manufacturing listed on the Indonesia Stock Exchange period of year 2009 to 2012. Samples were taken by purposive sampling and obtained 45 companies in the manufacturing sector as sample. Linear Regression Analysis with Simultaneous Significance Test ( $F$ statistic Test) and Individual Parameter Significance Test (Test Statistic t) is an analytical technique used in this study. The results showed that the independent variables of the debt ratio variable, size together significantly influence the price earnings ratio (PER) in the financial sector companies in the BEI and the independent variables of the dividend payout ratio and earnings growth together significantly influence price earnings ratio (PER) at manufacturing companies listed on BEI. These results support data obtained from the World Bank regarding Indonesia's economic growth in 2012 on the production side, manufacturing performance is quite strong. This increase was achieved by the relatively large performance domestic sectors such as those in processed foodstuffs, processed various beverages and processed various tobacco products (increasing $10.4 \%$ year on year) as well as fertilizer yields, yields from chemicals and rubber products (increased by $15.4 \%$ from year to year).
\end{abstract}

Keywords : Price Earning Ratio, Debt Ratio, Deviden Payout Ratio. Return On Equity, Pertumbuhan Laba, Ukuran Peerusahaan dan Perputaran Kas Operasi.

\section{PENDAHULUAN}

Bursa Efek Indonesia menjelaskan "Pasar modal memiliki peran penting bagi perekonomian suatu negara karena pasar modal menjalankan dua fungsi, yaitu pertama sebagai sarana bagi pendanaan usaha atau sebagai sarana bagi korporasi untuk mendapatkan dana dari masyarakat pemodal (investor)“. Menurut Santosa "Begitu banyaknya saham yang diperdagangkan di bursa 
saham mengakibatkan investor dihadapkan pada beberapa alternatif pilihan saham".

Price earning ratio merupakan keterkaitan antara pasaran harga saham dan laba untuk setiap lembar saham. Hasil price earning ratio yang tinggi dianggap bahwa korporasi tersebut sedang mengalami pertumbuhan yang pesat. Menurut Tryfino "Price earning ratio adalah rasio yang digunakan untuk menghitung tingkat pengembalian modal yang diinvestasikan pada suatu saham atau menghitung kemampuan suatu saham dalam mennghasilkan laba”.

Jika debt ratio suatu Korporasi berpengaruh positif maka sinyal positifpun akan dapat mempengaruhi investor dalam rangka mengambil keputusan investasinya, hal itu akan mempengaruhi nilai price earning ratio korporasi. Hal itu dapat memberi penjelasan bahwa debt ratio sangat penting dalam menganalisa nilai price earing ratio korporasi.

Pada korporasi yang bertumbuh tingginya pembayaran devidend menunjukkan sinyal positif bagi investor. Sebaliknya pada Korporasi yang kurang atau tidak bertumbuh, tingginya pemberian deviden memberikan sinyal atau isyarat negatif bagi Investor.

Kecenderungan bagi pemilik saham lebih tertarik pada korporasi yang mempunyai laba besar menggambarkan prospek bertumbuhnya korporasi tersebut, sehingga korporasi yang labanya meningkat akan membuat investor tertarik sehingga dapat memberikan pengaruh positif terhadap nilai Price Earning Ratio suatu korporasi. Oleh sebab itu tingkat pertumbuhan laba sangat penting dalam rangka menganalisa angka price earning ratio.

Kenaikan return on equity biasanya diikuti oleh kenaikan harga saham korporasi tersebut (Chrisna 2011:34). Menurut Chrisna "Semakin baik return on equity menandakan semakin baik pula kinerja suatu korporasi di dalam mengelola modalnya untuk menghasilkan keuntungan bagi Investor". Oleh karena itu return on equity sangat berperan untuk menganalisis price earning ratio.

Adanya anggapan bahwa skala suatu korporasi dapat berdampak pada laba korporasi, maka pemiik saham menginginkan return saham akan lebih 
meningkat dan perusahan yang mempunyai skala besarlah yang bisa memberi pengaruh pada nilai pasaran suatu saham korporasi dan bisa mempengaruhi price earning ratio korporasi. Oleh sebab itu ukuran korporasi dikatakan sangat penting dalam menganalisa nilai price earning ratio.

Aktivitas operasi memberikan indikasi bahwa kegiatan operasionalisasi korporasi dalam rangka mencukupi kasnya yang digunakan untuk membayar kewajiban, menjaga kelangsungan usaha, membayarkan deviden serta kegiatan investasi berikutnya dan bukan dana yang bersumber dari selain usaha. Tingginya perputaran kas dari hasil kegiatan operasional, maka tinggi pula korporasi dapat berkembang dan memberikan laba yang baik dihari depan. Oleh sebab itu bagi investor arus kas operasi merupakan hal yang sangat penting sebagai alat dalam memutuskan kegiatan berinvestasi sehingga dapat berpengaruh pada price earning ratio satu korporasi.

Perbedaan riset ini dengan penelitian sebelumnya adalah penelitian sebelumnya tidak menyertakan variable return on equity. Seperti diketahui bahwa return on equity merupakan angka psikologis bagi investor karena return on equity dijadikan indikator bagi investor untuk menilai kinerja korporasi untuk mengelola equitynya dan memmperoleh keuntungan pada investor. Berdasarkan latar belakang, maka judul penelitian ini adalah Analisis pengaruh faktor debt ratio, deviden pay out ratio, return on equity, pertumbuhan laba, ukuran korporasi, dan perputaran kas operasi pada PER.

\section{TELAAH LITERATUR DAN PENGEMBANGAN HIPOTESIS}

\section{Signaling Theory dan Teori Nilai Korporasi}

Menurut Brigham, 2013 “Teori Sinyal menjelaskan tentang bagaimana para investor memiliki informasi yang sama tentang prospek korporasi sebagai manajer korporasi ini disebut informasi asimetris, namum dalam kenyataannya manajer sering memiliki informasi lebih baik dari investor luar dan hal ini disebut informasi asimetris, dan ini memiliki dampak penting pada struktur modal yang optimal”. Menurut Jama'an, 2008 “Signaling theory 
mengemukakan tentang bagaimana seharusnya sebuah korporasi memberikan sinyal kepada pengguna laporan keuangan”.

\section{Teori Nilai Korporasi}

Menurut Suharli, 2009 "Salah satu hal yang dipertimbangkan oleh investor dalam melakukan investasi adalah nilai korporasi dimana investor tersebut akan menanamkan modal". Menurut Sudarman, 2010 "Fokus utama dalam penciptaan nilai adalah pada semua kesempatan dalam hal manajer ingin memanfaatkan secara penuh semua kesempatan yang ada untuk menilai saham atau sekuritas".

\section{Price Earning Ratio (PER)}

Menurut Syafri, 2010 "Pendekatan price earning ratio dicari melalui rasio antara harga pasar saham dengan laba perlembar saham". Riset ini mendasarkan pada price earning ratio, sebab price earning ratio ini merupakan informasi mengenai rentang waktu yang dibutuhkan sebagai cara untuk dapat meretur sejumlah rupiah pada level harga suatu saham dan laba korporasi pada satu waktu yang telah ditentukan. Menurut Syafri (2010 : 311) "rumus yang digunakan untuk menghitung price earning ratio adalah":

$\mathrm{PER}=\underset{\text { Harga saham }}{ }$

Earning / Share (Laba Perlembar Saham)

\section{Debt Ratio}

Menurut Santosa, 2009 "Korporasi umumnya memiliki sumber pendanaan untuk membiayai usahanya dari modal (equitas) dan hutang”. Menurut Wild, 2009 "motivasi utama korporasi :

1. "Bunga sebagian besar utang jumlahnya tetap, dan jika bunga dari pendanaan utang lebih kecil dari pengembalian yang diperoleh, selisih lebih atas pengembalian akan menjadi keuntungan bagi investor".

2. "Bunga merupakan beban yang dapat mengurangi pajak penghasilan sedangkan dividend tidak mengurangi pajak penghasilan".

\section{Devidend Payout Ratio}

Menurut Weston (2010: 125) "kebijakan deviden menentukan pembagian laba antara pembayaran kepada pembagian saham dan investasi kembali 
korporasi". Laba yang ditahan adalah sumber pendanaan yang sangat vital dalam kaitannya dengan keberlangsungan operasionalisasi korporasi, namun pada prakteknya keuntungan korporasi tersebut seringkali dimanfaatkan oleh pemegang saham untuk mendananai kepentingan pribadinya.

\section{Return On Equity}

Menurut Tandelin, 2010 "return on equity merupakan kemampuan korporasi dalam menghasilkan laba yang diperoleh pemegang saham". Rasio ini adalah hasil pembagian total keuntungan bersih dengan modal korporasi.

\section{Earning Growth / Pertumbuhan Laba}

Menurut Ikatan Akuntan Indonesia "Laporan laba rugi adalah laporan keuangan yang berisikan informasi tentang keuntungan atau kerugian yang diderita oleh korporasi dalam satu periode tertentu, pada laporan ini menyajikan data pendapatan sebagai hasil usaha korporasi dan beban sebagai pengeluaran operasional korporasi". Menurut Wild "laporan laba rugi adalah suatu laporan yang mengukur kinerja keuangan sebuah korporasi diantara tanggal neraca".

\section{Firm Size / Ukuran Korporasi}

Menurut Sawir, 2012 "ukuran korporasi adalah ukuran korporasi yang dapat menentukan tingkat kemudahan korporasi memperoleh dana dari pasar modal". Ukuran korporasi adalah gambaran yang diidentifikasikan dengan total aset, total pendapata, average jumlah pendapatan dan rata rata jumlah asset.

\section{Perputaran Kas Operasi}

Menurut Kieso, 2010 “Tujuan utama laporan arus kas adalah untuk memberikan informasi tentang penerimaan kas dan pengeluaran kas entitas selama suatu periode". Dengan mencermati perputaran kas aktivitas investasi dan pendanaan, seorang pengamat laporan keuangan dapat mengerti baik apakah aset dan hutang menjadi meningkat atau malah berkurang dalam satu waktu. 
Skema Kerangka Konseptual

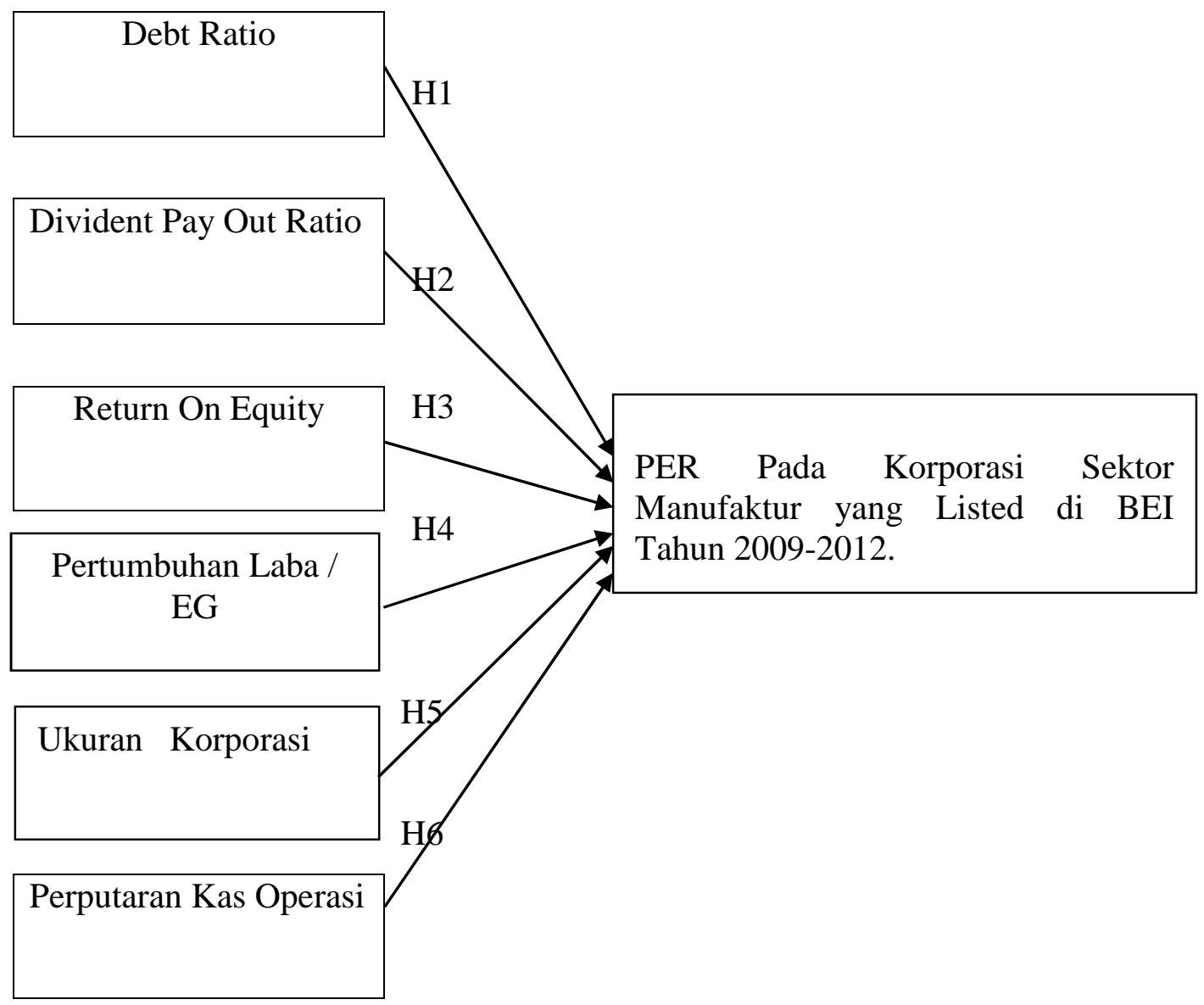

\section{Pengembangan Hipotesis}

Berdasarkan maksud dan tujuan riset ini, tinjauan riset sebelumnya dan hipotesa dari riset ini, maka hipotesa riset ini dapat rumus :

$\mathrm{H} 1=$ Debt ratio mempunyai pengaruh terhadap PER korporasi sektor manufaktur di BEI

$\mathrm{H} 2$ = Deveden payout ratio memiliki pengaruh terhadap PER korporasi sektor manufaktur di BEI.

$\mathrm{H} 3$ = Return on equity memiliki pengaruh terhadap PER korporasi sektor manufaktur di BEI.

$\mathrm{H} 4$ = Earning growth memiliki pengaruh terhadap PER korporasi sektor manufaktur di BEI.

H5 = Size memiliki pengaruh terhadap PER korporasi sektor manufaktur di BEI. 
H6 = Perputaran kas operasi memiliki pengaruh terhadap PER korporasi sektor manufaktur di BEI..

\section{METODE PENELITIAN}

Penggunaan data untuk menganalisa riset ini adalah kuantitatif data, Adapun dibutuhkan pada riset ini adalah dokumen financial report dari korporasi-korporasi disektor manufaktur yang ada di BEI dari 2009 hingga 2012. Dari perolehan data yaitu 45 korporasi disektor manufaktur yang listed di BEI selama kurun waktu 2009-2012.

\section{Operasional Variabel dan Pengukurannya}

\section{Dependen Variabel}

Menurut Brigham, 2013 "Price earning ratio menunjukkan seberapa banyak investor bersedia membayar per dollar laba yang dilaporkan adalah rasio harga pasar per saham terhadap laba per saham, dihitung menggunakan persamaan sebagai berikut":

Price Earning Ratio = Harga setiap lembar saham

$$
\text { Keuntungan saham tiap Lembar }
$$

\section{Independen Variabel :}

\section{Debt ratio atau leverage}

Menurut Brigham, 2013 "Debt ratio atau leverage merupakan rasio jumlah kewajiban dibagi jumlah aset, rasio ini dimanfaatkan dalam menilai dana yang harus disediakan oleh kreditur".

Faktor debt ratio = Jumlah Liabilitas /Jumlah Aset

\section{DPR}

Menurut Prastowo, 2002 "Rasio ini bisa dirumuskan dengan:

Deviden Payout Ratio $=\underline{\text { Deviden Per Share }}$

Earning Per Share

\section{Return on equity}

Rasio yang bisa dirumuskan dengan:

$R O E=\underline{\text { Keuntungan Sesudah Pajak }}$

Modal Pemilik Saham 


\section{Earning growth/Pertumbuhan Laba}

Rasio ini dirumuskan dengan:

$\mathrm{g}=\underline{\mathrm{EPSt}}-\mathrm{EPSt} .1$

EPSt.1

EPSt $=$ Laba ditahun $\mathrm{t}$

EPSt.1 = Laba sebelum terjadi ditahun $\mathrm{t}$

$\mathrm{g}=$ level tumbuhnya keuntungan

\section{Firm Size / Ukuran Korporasi}

Kaitannya dengan riset ini ukuran Korporasi diniliai dari total seluruh aset korporasi tersebut.

\section{Perputaran Kas Operasi}

Kaitannya dengan riset ini Perputaran kas merupakan angka yang dapat dilihat pada laporan arus kas yang dihasilkan dari kegiatan operasi yang bernilai positif.

\section{Pengukuran Variabel}

Dalam penelitian ini pengukuran variabel menggunakan skala rasio dan interval dimana melakukan kalkulasi aritmatik, dan pengukuran dimulai dari angka nol (merupakan bilangan riil).

\section{Teknik yang diguanakan dalam melakukan Pengumpulan Data}

Dalam memperoleh data pada riset ini digunakan cara pengumpulan arsip. Pengumpulan data arsip dalam penelitian ini berupa data sekunder, karena data tersebut sudah disediakan oleh korporasi publik sehingga peneliti dapat langsung menggunakannya. Data dikumpulkan dari laporan keuangan tahunan korporasi listed di BEI di sektor manufaktur yang telah telah dipublikasikan dari Tahun 2009 sampai dengan 2012 dan didapatkan dari ICMD 2012 dan website bei.

\section{Metode Analisis}

Data diolah dengan analisis multivariate regresi yang diaplikasikan dalam software SPSS v.21, oleh karenanya dapat terlihat masing-masing independent variable mempengaruhi dependent variabel. Menurut Ghozali, 
2013 "Sebelum data diolah dalam analisis rmultivariate regresi, data tersebut harus memenuhi uji asumsi klasik diantaranya" :

\section{Uji Normalitas}

Cara paling mudah dalam menilai normalitas dengan memanfaatkan histogram grafik yang dapat digunakan untuk mengkomparasi antara data yang observasi dengan pendekatan normal distribusi. Jika histogram grafik memperlihatkan pola seperti desain bel dan linear plot menunjukan data bergerak mengikuti linear line diagonal maka bisa diartikan bahwa data tersebut berdistribusi secara normal dan memenuhi syarat asumsi normalitas.

\section{Pengujian Multikolinearitas}

Menurut Ghozali, 2013 “Uji multikolinearitas bertujuan untuk menguji apakah model regresi ditemukan adanya korelasi antar variabel bebas". Multikolinearitas bisa diketahui melalui nilai tolerance dan juga variance inflation factor (VIF). Kedua parameter ini memperlihatkan independen variael manakah yang dapat dijelaskan oleh independen variabel lainnya.

\section{Pengujian Autokorelasi}

Autokorelasi timbul sebab observasi berjenjang dan saling berhubungan. Bainya suatu model regresi dapat diketahi dari terbebasnya unsdur autokorelasi. Agar dapat mengetahui ada atau tidaknya autokorelasi didalam satu regresi model dapat dilacak dengan memanfaatkan uji uji Durbin Watson. Jika angka DW ternyata lebih tinggi dari batasan atas (du) maka tidak ada autokorelasi didalam regresi model.

\section{Pengujian Heteroskedastisitas}

Menurut Ghozali, 2013 "Pengujian heteroskedastisitas digunakan sebagai alat agar tahu adanya penyimpangan atau tidak asumsi klasik heterokedastisitas yaitu adanya ketidaksamaan varian dari residual untuk semua pengamatan pada model regresi”. Menurut Ghozali, 2013 "ada beberapa cara yang digunakan untuk mengetahui terjadinya heterokesdastisitas atau tidak, salah satunya adalah dengan melihat grafik Scatterplot”. Menurut Ghozali, 2013 "Jika tidak ada pola yang jelas serta titik menyebar diatas dan dibawah angka 0 pada sumbu Y maka tidak terjadi heteroskedastisitas”. 


\section{Pengujian Linearitas}

Menurut Ghozali, 2013 "Pengujian ini dipergunakan sebagai alat untuk melihat kebenaran spesifikasi model. Dari pengujian ini didapatkan informasi apakah empirical model seharusnya linear, kuadrat atau kubik".

Model Persamaan dalam penelitian adalah sebag ini berikut :

$\mathrm{Y} 1=\alpha+\beta 1 . \mathrm{X} 1+\beta 2 . \mathrm{X} 2+\beta 3 . \mathrm{X} 3+\beta 4 . \mathrm{X} 4+\beta 5 . \mathrm{X} 5+\beta 6 . \mathrm{X} 6+\varepsilon$

$\mathrm{Y} 1=$ Price Earning ratio (PER) pada sektor finance

$\alpha=$ Konstanta

$\beta=$ Koefisien pada setia Independent Variable

X.1 = Debt Ratio

$\mathrm{X} .2=\mathrm{DPR}$

X.3 = Return On Equity

X.4 = Earning Growth / Pertumbuhan Laba

X.5 = Firm Size / Ukuran Korporasi

X.6 = Perpuaran Arus Kas Operasi

$\varepsilon=$ Disturbance error (faktor pengganggu residual)

H-1 sampai dengan H-6 harus di lakukan pengujian dengan alat uji t pada level signifikansi $5 \%$. Pengujian hipotesa dilaksanakan dengan komparasi antara angka t-hitung dengan angka t-tabel, jika angka t-hitung ternyata diatas dari angka t- table, $\mathrm{H}$-a diterima dan $\mathrm{H}$-o ditolak. Jika angka thitung ternyata diawah dari angka t- tabel maka $\mathrm{H}-\mathrm{a}$ ditolak dan $\mathrm{H}-\mathrm{o}$ diterima. Agar dapat tahu seberapa signifikan independent variable terhadap dependent variable secara bersamaan dilaksanakan dengan pengujian F. Pengujian $F$ dilaksanakan dengan cara komparasi antara angka F- hitung dengan angka Ftabel dengan level signifikansi $5 \%$, jika angka F-hitung berada diatas angka Ftable, analisisnya adalah $\mathrm{H}$-a diterima dan $\mathrm{H}$-o ditolak. Jika angka F-hitung berada dibawah angka F-tabel, analisisnya $\mathrm{H}$-a ditolak dan $\mathrm{H}$-o diterima. 


\section{HASIL PENELITIAN DAN PEMBAHASAN}

\section{Deskripsi Data Penelitian}

\section{Statistik Deskriptif Variabel Price Earning Ratio Pada Sektor Manufaktur}

Output deskripsi statistik terhadap nilai price earning ratio pada korporasi disektor manufaktur atau parikasi dapat ditunjukan didalam Tabel 4.1. didalam table tersebut jumlah $\mathrm{N}$ berjumlah 146 Angka PER teratas adalah 132.1100 dan angkai PER terbawah adalah 0.2400, angka rata-rata PER sebesar 13.909315 dan dtandar deviasinya adalah 13.2081814.

Tabel 4.1

Descriptive Statistics Sektor Manufaktur

\begin{tabular}{|l|r|r|r|r|r|}
\hline & \multicolumn{1}{|c|}{$\mathrm{N}$} & \multicolumn{1}{|c|}{ Minimum } & \multicolumn{1}{|c|}{ Maximum } & \multicolumn{1}{c|}{ Mean } & \multicolumn{1}{c|}{ Std. Deviation } \\
\hline PER & 146 & .2400 & 132.1100 & 13.909315 & 13.2081814 \\
DR & 146 & .0900 & .8600 & .405662 & .1856729 \\
DPR & 146 & .0000 & 2.6423 & .266178 & .3577184 \\
ROE & 146 & -.4078 & 13.2600 & .316880 & 1.0932495 \\
& 146 & -2.0000 & 37.0000 & .600474 & 3.1924554 \\
EG & & & & & \\
& & & & & \\
LnSIZE & 146 & 24.5400 & 34.2400 & 29.030342 & \\
LnOCF & 146 & 18.7100 & 33.1500 & 26.662671 & \\
Valid N & 146 & & & & \\
(listwise) & & & & & \\
\hline
\end{tabular}

Dokumen Sumber : dari olah data, 2014.

\section{Hasil Penelitian Pada Sektor Manufaktur}

Uji Asumsi Klasik Pada Sektor Manufaktur

\section{Uji Multikolinearitas}

Tabel 4.2

Koefisien Korelasi Antar Variabel Independent Coefficient Correlations ${ }^{\mathrm{a}}$

\begin{tabular}{|ll|r|r|r|r|r|r|}
\hline Model & & \multicolumn{1}{|c|}{ LnOCF } & \multicolumn{1}{c|}{ DR } & \multicolumn{1}{c|}{ ROE } & Dev.PR & \multicolumn{1}{c|}{ Ear.G } & \multicolumn{1}{c|}{ LnSIZE } \\
\hline \multirow{5}{*}{ Correlat. } & LnOCF & 1.000 & -.135 & -.031 & .000 & .087 & -.845 \\
& DR & -.135 & 1.000 & -.012 & -.016 & -.187 & .165 \\
& ROE & -.031 & -.012 & 1.000 & .056 & .012 & .014 \\
& DPR & .000 & -.016 & .056 & 1.000 & -.033 & -.097 \\
1 & EG & .087 & -.187 & .012 & -.033 & 1.000 & -.051 \\
& LnSIZE & -.845 & .165 & .014 & -.097 & -.051 & 1.000 \\
& LnOCF & .342 & -.362 & -.014 & .000 & .013 & -.382 \\
& DR & -.362 & 21.099 & -.041 & -.171 & -.227 & .587 \\
\multirow{3}{*}{ Covariances } & ROE & -.014 & -.041 & .575 & .100 & .002 & .008 \\
& DPR & .000 & -.171 & .100 & 5.545 & -.020 & -.177 \\
& EG & .013 & -.227 & .002 & -.020 & .070 & -.010 \\
& LnSIZE & -.382 & .587 & .008 & -.177 & -.010 & .599 \\
\hline
\end{tabular}

a. Dependent Variable: PER 
Dalam Tabel 4.2 tergambar bahwa antar setiap variabel tersebut tidak terlihat korelasi variable yang tinggi, korelasi paling tingggi adalah antara return on equity variable dan deviden payout ratio variabel adalah senilai 0.56 atau $56 \%$. Korelasinya masih kurang dari $95 \%$ oleh sebab itu dapat diartikan tidak adanya multikolinearitas.

Tabel 4.3

Koefisien Korelasi dan Var.Inflation Factor

Coefficients $^{\mathrm{a}}$

\begin{tabular}{|c|c|c|c|c|c|c|c|c|}
\hline \multirow{2}{*}{\multicolumn{2}{|c|}{ Model }} & \multicolumn{2}{|c|}{$\begin{array}{l}\text { Unstandardized } \\
\text { Coefficient }\end{array}$} & $\begin{array}{l}\text { "Standardized } \\
\text { Coefficient" }\end{array}$ & \multirow[t]{2}{*}{$\mathrm{T}$} & \multirow[t]{2}{*}{ Sig. } & \multicolumn{2}{|c|}{ Collinearity Statistics } \\
\hline & & $\mathrm{B}$ & Std. Error & Beta & & & Tolerance & VIF \\
\hline \multirow{7}{*}{1} & (Constant) & 33.409 & 12.795 & & 2.611 & .010 & & \\
\hline & DR & 2.818 & 4.593 & .040 & .613 & .541 & .940 & 1.064 \\
\hline & DPR & 24.678 & 2.355 & .668 & 10.480 & .000 & .964 & 1.038 \\
\hline & ROE & -.336 & .758 & -.028 & -.443 & 659 & .995 & 1.005 \\
\hline & EG & -.654 & .265 & -.158 & -2.468 & .015 & .957 & 1.045 \\
\hline & $\operatorname{LnSIZE}^{\wedge}$ & -1.220 & .774 & -.189 & -1.577 & .117 & .273 & 3.660 \\
\hline & LnOCF & .327 & .585 & .067 & .559 & .577 & .277 & 3.608 \\
\hline
\end{tabular}

a. Depend. Variable: P E R

Dokumen Sumber : Dari olah data, 2014.

Dari dalam Tabel 4.3 bisa terlihat mengenai result penghitungan tolerance value menjelaskan variabel yang mempunyai nilai tolerance value dibawah dari 0,10 itu tidak ada, artinya tidak terdapat hubungan antara independent variable yang anggkanya diatasi $95 \%$. Perhitungan VIF ternyata menjelaskan bahwa anka VIF teratas ada di variabel $\mathrm{Ln} \mathrm{Size}^{\wedge}$ se niai 3.660. Hal ini diartikan tidak ada satupun independen variable yang mempunyai nilai VIF diatas 10 . Disimpulkan bahwa tidak ada multikolinieritas pada independen variable didalam regresi model ini.

\section{Pengujian Autokorrelasi}

Agar dapat tahu ada unsur autokorrelasi didalam regresi model bisa dilakukan pendeteksian yaitu melakukan uji Durbbin Watson (DW-test). Jika angka D-W ternyata diatas dari batas paling atas (du) ini berarti tidak ada unsur autokorelasi didalam regresi model ini. 
Tabel 4.4

Hasil Pengujian Durbin - Watson

Summary $^{b}$

\begin{tabular}{l|r|r|r|r|r|}
\hline Model & R. & R- Square & $\begin{array}{c}\text { Adjusted. } \\
\text { R.Square }\end{array}$ & $\begin{array}{r}\text { Std. Error-of the- } \\
\text { Estimate }\end{array}$ & Durbin-Watson \\
\hline 1 & $.675^{\text {a }}$ & .455 & .432 & 9.9577490 & 1.879. \\
\hline
\end{tabular}
a. Predict: (Constant.), LnOCF, DR, ROE, DPR, EG, LnSIZE
b. Dependent Variable: PER

Dalam Tabel 4.4 diatas terlihat angka D-W senilai 1.879. nilai dikomparasi menggunakan tabel D-W yang mana tingkat siggnifikansinya $5 \%$. Dalam tabel D-W didapat angka teratas (du) adalah 1.816. Sebab angka D-W 1.879 diatas batas teratas (du) 1.816, maka dapat dikatakan bahwa tidak terdapat autokorelasi.

\section{Pengujian Heteroskedastisitas}

Heterokedastisitas riset ini, regresinya dilakukan pengujian dengan memperhatikan Grafik-Plot (Scatterplot) dan agar dapat lmemberi kepastian lebih tidak ada heterokedastisitas maka dilakukan pengujian statistik yang dikenal sebagai Uji-Glejser.

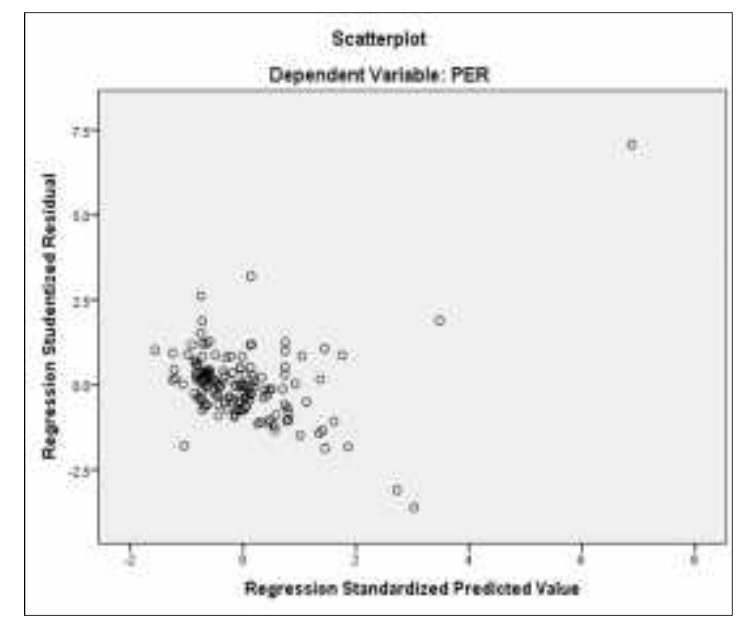

Sumber : Hasil olahan data sekunder

Gambar 4.1

SCATTEERPLOT

Berdasar grafik 4.1 terlihat beberapa titik tersebar dengan tidak beraturan dan menyebar diatas angka nol dan dibawah angka nol di sumbu Y. Oleh 
Sebab itu hal ini bisa mamberi kesimpulan disini tidak ada heterokedastisitas pada regresi model ini. Agar pengujian heterokedastisitas agar dapat dipasikan keakuratannya, dilakukan pengujian dengan pengujian statistik yang dikenal pengujian glejser. Pengujian glejser dapat dilaksanakan melalui teknik regresslah angka residual absolut dengan independen variabel.

\section{Tabel 4.5}

\section{Hasil Pengujian-Glejser}

Coefficients.

\begin{tabular}{|c|c|c|c|c|c|}
\hline \multirow[t]{2}{*}{ Model } & \multicolumn{2}{|c|}{ Unstandardized- Coefficients } & \multirow{2}{*}{$\begin{array}{l}\text { Standardized } \\
\text { Coefficients } \\
\text { Beta- }\end{array}$} & \multirow[t]{2}{*}{$\mathrm{t}$} & \multirow[t]{2}{*}{ Sigg. } \\
\hline & B. & Std. Error* & & & \\
\hline (Constant.) & 13.687 & 7.068 & & 1.936 & .055 \\
\hline DR & 1.957 & 2.537 & .050 & .771 & .442 \\
\hline DPR & 13.396 & 1.301 & .664 & 10.298 & .000 \\
\hline $1 \mathrm{ROE}$ & -.057 & .419 & -.009 & -.136 & .892 \\
\hline EG & -.285 & .146 & -.126 & -1.948 & .053 \\
\hline LnSIZE & -.007 & .428 & -.002 & -.017 & .986 \\
\hline $\mathrm{LnOCF}$ & -.417 & .323 & -.155 & -1.290 & .199 \\
\hline
\end{tabular}

Sumber : data sekunder yang telah diolah, 2014.

Dari tabel 4.15 dapat terlihat bahwa terdapat satu variable yang tingkat signifikansinya $<0.05$ yaitu deviden payout ratio tetapi secara dominan variable-variabel independen lainnya lolos dari uji heteroskesdastisitas sebab tingkat signifikansinya diatas 0.05 .

\section{Uji Normalitas}

Cara paling mudah dalam menilai normalitas-residual ini yaitu dengan cara mempergunakan histogram-graik, bertujuan mengkomparasi data yang diteliti dengan distriibusi yang didekatkan dengan normal distribusi. Jika histogram-grafik memperlihatkan desain yang berbentuk lonceng dan linear plot menunjukkan data secara linear-diagonal bergerak mengikuti hal itu di tarik kesimpulan data tersebut berrdistribusi secara normal, dapat syarat normalitas. 


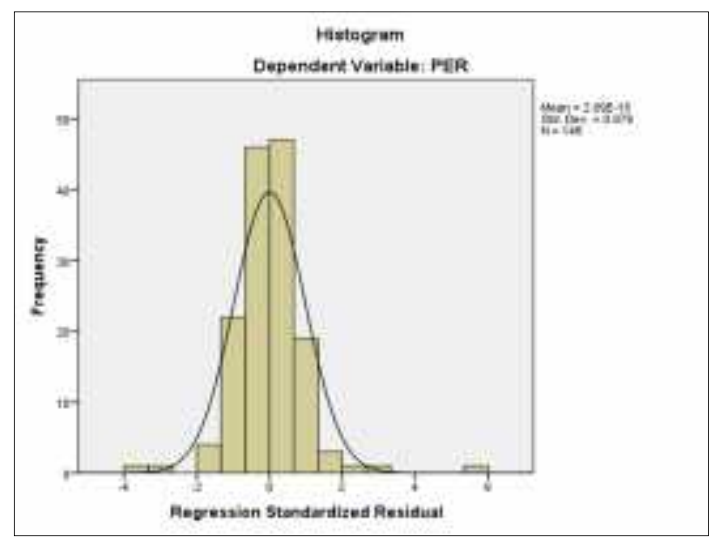

Sumber : Hasil olah data, 2014.

Gambar 4.2

Histogram-Grafik Pengujian Normalitas

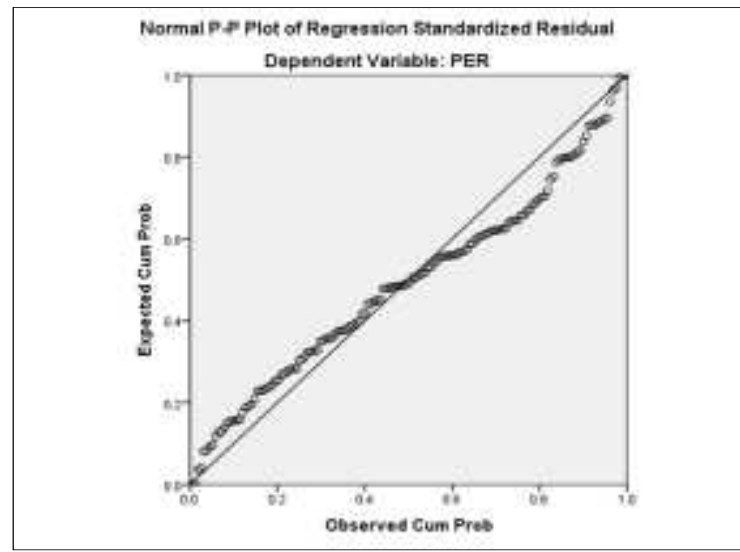

Gambar 4.3

P.Plot Pengujian Normalitas

Dari Gambar 4.2, 4.3 ditampilkan histogram-grafik simetris sedangkan plot grafik memperlihatkan titik menyerupai diagonal line, oleh karena itu dikatakan data tersebut berdistribusi secara norrmal. Untuk mengetahui lebih akurat mengenai data tersebut berdistribusi secara normal maka harus dilaksanakan penguujian statistik, dalam riset ini pengujian statistik yang dipakai yaitu dengan melakukan pengujian statistik nonparametrik Kolmogorov-Smirrnov. 
Tabel 4.6

Hasil Pengujian Statistic Non-Parametric Kolmogorov-Smirrnov

Sample Kolmogorov-Smirrnov Test

\begin{tabular}{|ll|r|}
\hline $\mathrm{N}$ & & Unstandardized- Residual \\
\hline Normal-Parameters & 146 \\
& Mean & .0000000 \\
& Std. Deviation & 9.74955011 \\
Most-Extreme Differencess & Absolute & .107 \\
& Positive & .107 \\
Kolmogorov-Smirrnov Z & Negative & -.073 \\
Asymp.Sig. (2tailed.) & & 1.288 \\
\hline
\end{tabular}

Sumber : Hasil Olah Data, 2014

Dari Tabel 4.16 dapat dilihat nilai Kolmogorov-Smirnov adalah 1.288 tingkat signifikansinya diangka 0.73 artinya pendistribusian data secara normal telah terjadi di dalam data residual ini. Dari paparan tersebut merupakan hasil dari ujia statistik non-parameetrik Kolmogorov-Smirrnov telah mendukung hasil ujia histogram grafik dan ujia $P$-Plot, karenanya kesimpulan uji ini data residual telah terdistribusi dengan normal dan regresi model ini sudah sebagai syarat asumsi normalitas.

\section{Uji Linearitas}

Dalam penelitian ini uji linearitas yang digunakan adalah uji langrange multiplier ysng bertujuan untuk mendapatkan nilai c2 hitung atau (nxR2) (Ghozali, 2013). Berdasarkan Tabel 4.17 dapat dilihat hasil output yang ditampikan menunjukan nilai R2 sebesar 0.000 jumlah n observasi 146, jadi besarnya c2-hitung $=146 * 0.000=0$. Kemudian nilai ini dikomparasikan c-2 tabel, $\mathrm{df}=146$, tingkat signifikansinya $=0.050$ diperoleh nilai $\mathrm{c}-2$ tabel $=$ 175.848. Oleh sebab nilai c-2 diawah niai c-2 tabel yang ada ditabel, memberi kesimpulkan tentang model yang dianggap benar yaitu linear model.

Tabel 4.7

Hasil Uji Linearitas (Langrange Multiplier) Models Summary

\begin{tabular}{l|l|l|r|r|}
\hline Model & R. & R-Square & $\begin{array}{c}\text { Adjusted. R- } \\
\text { Square }\end{array}$ & $\begin{array}{c}\text { Std. Error of- the } \\
\text { Estimate. }\end{array}$ \\
\hline 1 & $.000^{\mathrm{a}}$ & \multicolumn{2}{|c|}{-.000} & 9.95774904 \\
\hline
\end{tabular}




\section{Hasil Pengujian}

Tabel 4.8

Pengujian Koefisien - Determinasi

Models Summary ${ }^{\mathrm{b}}$

\begin{tabular}{|l|r|r|r|c|}
\hline Mode'l & \multicolumn{1}{|c|}{ R. } & R- Square & Adjusted R- Square & $\begin{array}{c}\text { Std. Error of- the } \\
\text { Estimate }\end{array}$ \\
\hline '1 & $.675^{\mathrm{a}}$ & .455 & .432 & 9.9577490 \\
\hline
\end{tabular}

a. Predictors: (Constant), LnOCF, DR, ROE, DPR, EG, LnSIZE

Berdasarkan output yang ditampilkan oleh SPSS software di Tabel 4.8 Adjusted $R$ - Square adalah 0.432 , ini artinya $43.2 \%$ price earning ratio variabel bisa dijelaskan oleh independen variael debt ratio, DPR, return on equity, EG, ukuran korporasi dan perputaran kas dari hasil operasi, sedangkan variabel lain menjelaskan sisanya yang belum atau tidak diteliti dalam regresi model ini. Standar Error of-Estimate sebesar 9.95774904 membuktikan bahwa besarnya kemungkinan terjadinya kesalahan regresi model ini dalam rangka menjelaskan dependent variabel independent ini.

Tabel 4.9

Hasil Pengujian Signifikansi-Simultan (Pengujian Statistik-F) ANOVA.

\begin{tabular}{|l|r|r|r|r|r|}
\hline Models & Sum of- Squares & \multicolumn{1}{|c|}{ Df. } & Mean- Square & \multicolumn{1}{l|}{ F. } & \multicolumn{1}{c|}{ Sig. } \\
\hline Regression. & 11513.338 & 6 & 1918.890 & 19.352 & $.000^{\mathrm{b}}$ \\
$1 \quad$ Residual & 13782.790 & 139 & 99.157 & & \\
\multicolumn{1}{|l}{ Total } & 25296.128 & 145 & & & \\
\hline
\end{tabular}

a. Dependent-Variable: PER

b. Preedictors: (Constant), LnOCF, DR, ROE., DPR, EG., LnSIZE

Sumber : Hasil olah data Skunder

Dari pengujian ANOVA diperoleh nilai F-hitung adalah 19.352 dan probabilitasnya 0,000. Probabilitas itu lebih kecil disbanding angka 0.05 dan dapat diartikan bahwa debt ratio, DPR, return on equity, EG, size, dan perputaran kas dari operasi secara simultan memiliki pengaruh terhadap PER. 
Tabel 4.10

Hasil Pengujian Signifikansi Parameter Individuals

(Pengujian Statistik- t)

\begin{tabular}{|c|c|c|c|c|c|}
\hline \multirow[t]{2}{*}{ Models } & \multicolumn{2}{|c|}{ Unstandardized- Coefficient } & \multirow{2}{*}{$\begin{array}{c}\begin{array}{c}\text { Standardized- } \\
\text { Coefficient }\end{array} \\
\text { Beta. }\end{array}$} & \multirow[t]{2}{*}{$\mathrm{T}$. } & \multirow[t]{2}{*}{ Sigg. } \\
\hline & $\mathrm{B}$ & Std.- Error & & & \\
\hline (Constant.) & 33.409 & 12.795 & & 2.611 & .010 \\
\hline DR & 2.818 & 4.593 & .040 & .613 & .541 \\
\hline DPR & 24.678 & 2.355 & .668 & 10.480 & .000 \\
\hline $1 \mathrm{ROE}$ & -.336 & .758 & -.028 & -.443 & .659 \\
\hline EG & -.654 & .265 & -.158 & -2.468 & .015 \\
\hline LnSIZE & -1.220 & .774 & -.189 & -1.577 & .117 \\
\hline LnOCF & .327 & .585 & .067 & .559 & .577 \\
\hline
\end{tabular}

a. Dependent Variable: PER

Dari Tabel 4.10 Hasil pengujian signifikansi paarameter Individual (Pengujian Statistik- t) bisa diperoleh persamaan regresinya dari riset ini : $\mathrm{PER}=33.409+2.818 \mathrm{DR}+24.678 \mathrm{DPR}-0.336 \mathrm{ROE}-0.654 \mathrm{EG}-$ 1.220LnSIZE+ 0.327LnOCF.

Tabel 4.10 memperlihatkan hasil pengujian-t, yang kemudian diperbandingkan dengan angka t tabel tingkat signifikansi $(\alpha) 5 \%$. Variabel debt ratio memiliki koefisien regresi sebesar 2.818 dengan nilai t hitung sebesar 0.613 pada tingkat signifikansi 0.541 jauh lebih besar daripada $5 \%$. Oleh karenanya dapat dikatakan HA1 ditolak, H01 dapat diterima yang menyatakan faktor debt ratio tidak memiliki pengaruh yang signifikan pada PER.

Variabel $D P R$ mempunyai koeffisien regresi senilai 24.6782 nilai t-hitung 10.480 dengan level signifikansinya 0.000 kurang dari 5\%. Oleh karenanya dapat diartikan HA1 diterima, H01 ditolak dan menyimpulkan bahwa DPR mempunyai pengaruh yang signifikan terhadap PER.

Variabel return on equity mempunyai koeffisien regresi diangka -0.336 nilai t-hitung -0.443 tingkat signifikansinya 0.659 diatas $5 \%$. Oleh karenanya disimpulkan HA1 ditolak, H01 dapat diterima yang menyatakan faktor return on equity tidak memiliki pengaruh yang signifikan pada $P E R$.

Variabel Pertumbuhan Laba (EG) mempunyai koeffisien regreesi diangka -0.654 t- hitung -2.468 tingkat signifikansinya 0.015 dibawah $5 \%$. Oleh 
karenanya dikatakan HA1 diterima, H01 Ditolak yang menyatakan faktor earning growth memiliki pengaruh yang signifikan PER.

Variabel LnSize mempunyai koeffisien regreesi diangka -1.220, t- hitung sebesar 0.327 pada tingkat signifikansi 0.117 lebih besar dari 5\%. Dengan demikian dapat dikatakan bahwa HA1 ditolak, H01 diterima. Oleh karenanya ukuran korporasi tidak memiliki pengaruh yang signifikan Pada PER.

Variabel perputaran kas operasi (Ln OCF) mempunyai koeffisien regressi diangka -0.327 t-hitung 0.559 tingkat signifikansinya 0.577 diatas $5 \%$. Oleh karenanya dapat disimpulkan HA1 ditolak, H01 dapat diterima yang menyatakan Faktor Ln $O C F$ tidak memiliki pengaruh yang signifikan Pada PER.

Apabila ditinjau, angka signifikansi dari variable debt ratio, return on equity, Ln size, perputaran kas dari operasi (Ln $O C F)$ tidak memiliki pengaruh yang signifikan pada PER. Hal tersebuti dapat dibuktikan angka signifikansi debt ratio 0,541 , return on equity 0.659 , Ln Size 0.117 dan arus kas operasi (Ln $O C F$ ) 0.577 yang jauh diatas 0.050 , sedangkan $D P R$ angka signifikansinya berada pada 0.000 , earning growth angka signifikansinya berada pada 0.015 yang jauh lebih kecil dari 0.050, oleh karenanya dapat dinarasikan DPR dan LnSize secara masing-masing memiliki pengaruh yang signifikan Pada PER.

\section{Pengaruh Debt Ratio Pada PER}

Hasil riset ini mengenai pengaruh debt ratio pada $P E R$ menggambarkan debt ratio variable tidak memiliki pengaruh yang signifikan terhadap PER. Penemuan ini mensupport penemuan dari riset yang dilakukan oleh Khanh Ly (2013), Samya Tahir (2012), Rossje Surya Putri Cristina pada 1999 yang menyimpulkan PER tidak mendapatkan pengaruh yang siginifikan oleh variabel debt ratio. Hal tersebut tidak sama dengan penemuan sebelumnya yaitu riset yang dijalani Yudi Santosa (2009), Luthan dan Rofiqoh (2004), bahwa faktor leverage Korporasi berpengaruh peositif terhadap PER Korporasi. Hasil penemuan dari penelitan tersebut ternyata tidak sama dengan teori dan riset pada umumnya yang menyatakan Investor yang berorientasi pada laba perlembar saham lebih tinggi cenderung menginginkan korporasi 
yang mempunyai debt ratio atau leverage yang tinggi tentunya diharapkan debt ratio atau leverage dapat berpengaruh secara positif (jika revenue yang diperoleh korporasi akan lebih tinggi daripada beban yang dikeluarkan untuk menggunakan Cash yang ada). Debt ratio korporasi dapat menimbulkan pengaruh yang baik, pemegang saham akan mendapatkan arahan tersebut maka memeerikan berpengaruh secara positif pula pada nilai price earning ratio Korporasi.

\section{Pengaruh DPR Pada PER}

Hasil riset ini mengenai pengaruh divident payout ratio terhadap PER memberi petunjuk bahwa price earning dipengaruhi oleh divident payout ratio ratio. Penemuan tersebut sejalan dengan penemuan terdahulunya adalah riset yang dilakukan Khanh Ly (2013), Samya Tahir (2012) divident payout ratio mempunyai pengaruh positif yang signifikan terhadap price earning ratio dan juga penelitian yang dilakukan oleh Yudi Santosa (2009) yang menyatakan bahwa divident payout ratio mempunyai pengaruh positif yang signifikan terhadap price earning ratio. Riset tersebut menjelaskan bahwa keterjadian ini disebabkan di korporasi yang berkembang tingkat dividen tinggi menjadi signal yang baik untuk pemegang saham yang mengisyaratkan bahwa korporasi mempunyai prospek yang bagus dan berpotensi mendapatkan laba lebih besar kedepannya.

\section{Pengaruh ROE Pada PER}

Hasil penelitian ini mengenai keterkaitan pengaruh variabel return on equity terhadap PER menggambarkan price earning ratio tidak dipengaruhi secara signifikan oleh variabel return on equity. Hal ini bertolak belakang dengan penelitian dan teori pada umumnya yang menyatakan bahwa return on equity mempunyai pengaruh yang positif terhadap price earning ratio sehingga akan mempengaruhi investor dalam melakukan kegiatan investasinya. Oleh karena memang hasil olah data ini menghasilkan kesimpulan yang berbeda maka dapat dikatakan bahwa return on equity tidak selamanya mempengaruhi variable price earning ratio. Hasil riset ini berbeda dari temuan Yuehong dan 
Jianxin (2011) yang menyatakan return on equity memiiki pengaruh positif terhadap PER.

\section{Pengaruh Earning Growth Pada PER}

Hasil riset ini mengenai adanya keterkaitan pengaruh variabel earning growth atau pertumbuhan laba pada PER menggambarkan bahwa PER dipengaruhi secara signifikan oleh variabel earning growth atau pertumbuhan laba, hasil riset tersebut sama dengan hasil riset Yudi Santosa (2009) yang menerangkan variabel earning growth ternyata memiiki pengaruh signifikan pada price earning ratio di mayoritas korporasi di BEJ. Hasil dari penelitian tersebut juga seirama dengan riset yang dilakukan Luthan dan Rofiqoh (2004) dan riset yang dilakukan Murtini (2002) yaitu menerangkan variabel earning growth atau pertumbuhan laba memiliki pengaruh yang signifikan pada variabel price earning ratio. Tetapi hasil riset ini tidak senada dengan penemuan riset yang dilaksanakan oleh Samya tahir (2012), Rossje V. Surya Putri dan Cristina pada tahun 1999, bahwa pertumbuhan laba atau earning growth tidak memiliki pengaruh yang siginifikan pada price earing ratio Hasil penelitian sebelumnya yang menyebutkan bahwa variable earning growth mempunyai pengaruh signifikan pada price earning ratio menjelaskan semakin besar nilai pertumbuhan laba atau earning growth, mengakibatkan akan makin besar juga nilai dari price earning ratio. Perisiwa ini dikarenakan seorang penanam modal lebih tertarik pada korporasi labanya semakin besar sehingga menandakan adanya ruang bagi korporasi dapat berkembang, oleh karenanya investor akan merespon positif korporasi yang mempunyai pertumbuhan laba yang meningkat yang akan memberi dampak pada peningkatan price earning ratio korporasi.

\section{Pengaruh Ukuran Korporasi Pada Price Earning Ratio}

Riset mengenai pengaruh variabel ukuran korporasi atau size pada price earning ratio menggambarkan size variable tidak memiliki pengaruh yang signifikan terhadap price earning ratio, penemuan ini berbeda dengan temuan pada penelitian yang dilakukan oleh Samya Tahir (2012), penelitian yang dilakukan Yudi Santosa (2009), penelitian yang dilakukan Luthan Rofiqoh 
(2004) dan riset yang dilakukan Murtini, (2002) yang menghasilkan size variale memiliki pengaruh yang baik pada price earning ratio. Hal tersebut dapat terjadi sebab pada umumnya size variable korporasi menggambarkan seberapa mampu sebuah korporasi dapat membiayai operasionalisai dan kegiatan investasi dengan harapan dapat memberikan laba bagi korporasi, sehingga ada anggapan bahwa makin besarnya ukuran korporasi maka akan besar pula pendapatannya. Penanam modal cenderung menginginkan return ttinggi dan memilih korporasi berskala besar, hal tersebut dapat berpengaruh terhadap nilai pasaran saham korporasi juga bisa menaikkan value price earning ratio. Didalam penelitian ini tidak menghasilkan temuan yang tidak sejalan dengan teori dan penelitian pada umumnya. Hal ini dapat memberikan pemahaman bahwa tidak selamanya ukuran korporasi dapat dijadikan sebagai alat untuk menilai price earning ratio sebuah Korporasi.

\section{Pengaruh Perputaran Kas Operasi Pada Price Earning Ratio}

Riset ini mengenai pengaruh perputaran kas operasi pada price earning ratio mennjelaskan bahwa price earning ratio tidak dipengaruhi secara signifikan oleh perputaran kas dari operasi, ada kemungkinan yang menyebabkan hal ini dapat terjadi adalah salah satunya investor kurang atau tidak melihat informasi yang terdapat didalam laporan arus kas dai roperasi yang maksimal, sehingga peningkatan maupun penggurangan arus kas dari aktivitas operasi tidak memiliki pengaruh yang signifikan pada price earning ratio value Korporasi. Riset ini menggambarkan makin tinggi nilai operation cashfllow, akan makin rendah pula price earning ratio. Koefisien regresi dari variabel operation cashfllow adalah 0.327 memberi gambaran setiap 1\% kenaikan variable operation cashfllow $32.7 \%$ akan turun nilai price earning ratio bersyarat besaran variabel lain adalah tetap. Hasil penelitian riset ini tidak sama pada teori yang menjelaskan arus kas dari operasi memiliki pengaruh yang baik terhadap price earning ratio sehingga akan berpengaruh positif juga pada nilai price earning ratio. Hal tersebut tidak sama dengan temuan Yudi Santosa, 2009 yang menyebut arus kas dari operasi memiliki pengaruh yang positif terhadap price earning ratio. 


\section{SIMPULAN}

Hasil dari uji statistik memberi kesimpulkan antara lain :

a. Faktor devident payout ratio dan earning growth secara bersama-sama berpengaruh secara signifikan pada price earning ratio di korporasi sektor manufaktur listing di BEI dalam kurun waktu 2009 sampai dengan 2012.

b. Faktor debt ratio, return on equity, size dan arus kas dari operasi tidak memiliki pengaruh yang signifikan pada price earning ratio di korporasi sektor manufaktur yang listing di BEI dalam kurun waktu 2009 sampai dengan 2012.

\section{Keterbatasan}

Riset ini memiiki keterbatasan :

1. Penelitian dilaksanakan dalam waktu kurang panjang hanya dalam empat tahun dan didapat sample sebanyak 146 sample disektor manufaktur yang memenuhi kriteria pangambilan sampel.

2. Penelitian ini tidak membandingkan secara detail antar sektor, hanya berupa penjelasan saja.

\section{REFERENSI}

Brigham, Uegene F dan Houston,Joel. 2013. Dasar-Dasar Manajemen Keuangan. Jakarta : Erlangga.

Bursa Efek Indonesia, 2010.

Chrisna, Heriyati. (2011). Pengaruh Return On Equity,Net Interest Margin dan Dividend Payout Terhadap Harga Saham Perbankan di Bursa Efek Indonesia. Magister Akuntansi Sekolah Pascasarjana Universitas Sumatera Utara.

Ghozali, Imam, 2013. Analisis Multivariate dan Program SPSS. Semarang: Badan Penerbit Universitas Diponegoro.

Ikatan Akuntan Indonesia, 2013.

Jama'an. 2008. Pengaruh Mekanisme Corporate Governance, Dan Kualitas Kantor Akuntan PublikTerhadap Integritas Informasi Laporan Keuangan. Thesis. Semarang: Program Studi Magister Sains Akuntansi Universitas Dipenegoro. 
Santosa Yudi, 2009. Analisis Pengaruh leverage, dividen payout ratio, size, earning growth dan arus kas terhadap price earning ratio pada korporasi yang listed di BEI tahun 2004 - 2006. Thesis. Semarang : Universitas Diponegoro.

Suryaputri, V. Rossje, Cristina . 2003. Pengaruh Faktor Leverage, Devidend Payout, Size, and Country Risk terhadap Price Earning Ratio. Media Riset Akuntansi, Auditing, dan Informasi, Vol. 1 April 2003.

Tahir, Samya, 2012. Determinants of Price-Earnings Ratio: The Case of Chemical Sector of Pakistan. International Journal of Academic Research in Business and Social Sciences.

Tryfino, 2009. Cara Cerdas Berinvestasi Saham. Jakarta: Transmedia Pustaka. Yuehong dan Jianxin, 2012. Empirical Study on the Main Factors Affecting Price-Earning Ratio of Listed Companies in China. College of Economy and Management, Henan Polytechnic University, P.R.China, 454000 . 